\title{
From headache to Rathke's cleft cyst followed by diabetes insipidus with panhypopituitarism
}

${ }^{1}$ Department of Endocrinology, Iuliu Hatieganu University of Medicine and Pharmacy \& Clinical County Hospital, Cluj-Napoca, Romania

${ }^{2}$ Department of Endocrinology, Cluj-Napoca Clinical County Hospital, Romania

${ }^{3}$ Department of Endocrinology, Carol Davila University of Medicine and Pharmacy, Bucharest \& C.I. Parhon National Institute of Endocrinology, Bucharest, Romania

\begin{abstract}
Introduction

The Rathke cyst represents an unusual benign tumour derived from Rathke's cleft remnants. The diagnosis is potential seen at any age. The most frequent signs are mostly mass effects as headache, visual field defects and hypopituitarism.

Case presentation

30-year old female is admitted for persistent headache that was later associated with secondary amenorrhea and visual field defects for the last two years. The clinical data are consistent with high levels of serum prolactin, gonadotropes deficiency, as well as central hypothyroidism. The magnetic resonance imagery found a pituitary tumour of 2.7 centimetres with extrapituitary extension up to the optic chiasm. Surgery was performed in order to remove the tumour. The pathologic report confirmed a Rathke's cleft cyst. Diabetes insipidus associated with panhypopituitarism was diagnosed and treated after the procedure. Close follow-up is necessary.

\section{Conclusion}

This case highlights the fact that headache sometimes embraces a severe neoplasia diagnosis and that the
\end{abstract}

\section{Mara Carsote}

Bucharest, Romania, Aviatorilor Ave 34-38, sector 1, postal code 011863 fax: +40213170607 ;

phone: +40213172041 ;

email: carsote_m@hotmail.com iatrogenic complications after surgery are lifelong care demanding.

Keywords: pituitary tumour, Rathke's cleft, diabetes insipidus, panhypopituitarism, headache

\section{Introduction}

Rathke's clef cyst represents an atypical benign sellar or suprasellar tumour that arises from the remnants of Rathke's pouch.[1,2,3] A failure of pouch obliteration results in cysts or cystic remnants at the interface between the anterior and posterior pituitary. $[2,3,4,5]$ It has a mixed content, usually with a small size but it can reach up to 4 centimetres. $[3,4,5,6]$ Most Rathke's cleft cysts do not associate any noticeable symptoms and they are incidentally discovered at magnetic resonance image (MRI) or computed tomography (CT) scan when they are performed for another reasons.[5,6,7] In case of Rathke cleft cyst associated symptoms the most common are headaches, visual disturbances, and galactorrhea.[1] Also hypopituitarism can be caused by compression of adjacent pituitary tissue or pituitary stalk.[1] The main differential diagnoses are done with other brain masses like: craniofaringioma, pituitary adenoma, arachnoid cyst, epidermoid cyst, teratoma. $[1,5,6,7,8]$ 
Surgical treatment is indicated for symptomatic cases. [1] The postoperative prognostic is good, clinical remission in seen in a high number of cases. $[1,9,10]$

\section{Gase presentation}

30 year-old female patient was admitted in 2013 for secondary amenorrhea, bitemporal hemianopsia and headache not responding to minor analgesics. The clinical examination showed a $160 \mathrm{~cm}$ height and 52kilograms $(\mathrm{kg})$ weight, blood pressure of $90 / 70 \mathrm{mmHg}$ with a regular sinus rhythm of 60 beats per minute, normal examination of respiratory and gastrointestinal systems. The endocrine evaluation revealed hyperprolactinemia, pituitary gonadotroph and tyrotroph insufficiency. (Table I) Up to the moment of admission she has been seen a different endocrine centre and received treatment with levothyroxine and dopamine agonist cabergoline.

Pituitary MRI demonstrated an oval mass of 24 by 15 by $27 \mathrm{~mm}$ with compression of pituitary stalk and pituitary gland associating suprasellar extension and moderate compression of the optic chiasm and bilateral carotid sinus. These findings suggested the presence of a pituitary adenoma with necroses and cystic transformation or a pituitary abscess. (Figure
1)

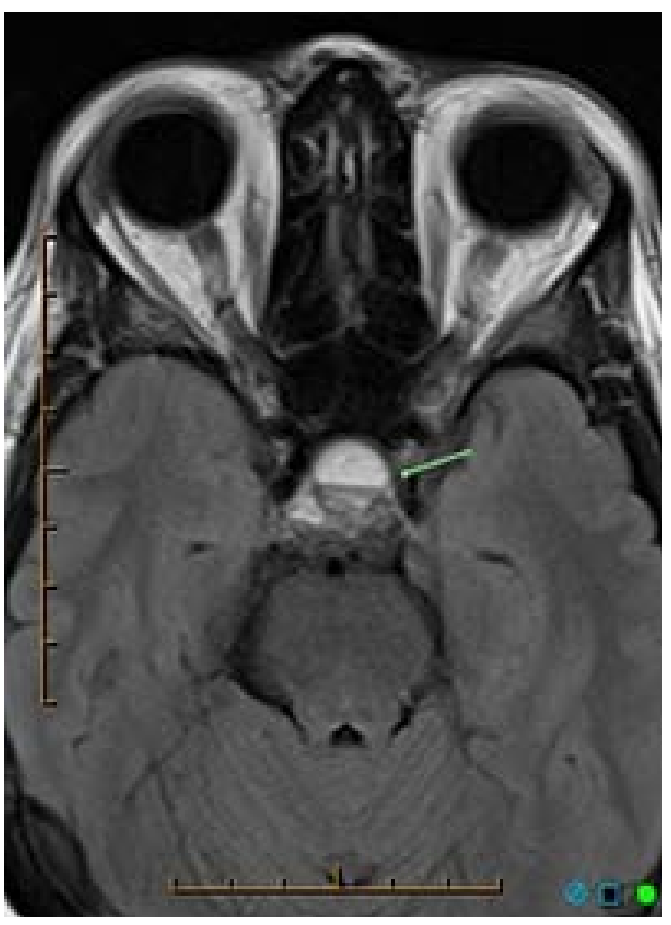

Figure1. MRI in a 30-year old female with Rathke's cleft cyst

In April 2014 pituitary surgery is performed with fully ablation of the tumour. The pathologic result was Rathke's clef cyst. Postoperative she received oral glucocorticoids, levothyroxin of daily

Table I: Biochemical and hormonal values in 30-year old female with visual field defects, secondary amenorrhea, and persistent headache

\begin{tabular}{|l|c|c|c|r|}
\hline Parameter & Pre operatory & 1 month post operatory & 1 year post operatory & Normal ranges \\
\hline TSH & 1.66 & NA & 0.02 & $0.4-4 \mathrm{microUI} / \mathrm{ml}$ \\
\hline FreeT4 & 0.57 & 0.43 & 0.86 & $0.89-1.76 \mathrm{ng} / \mathrm{dl}$ \\
\hline Prolactin & 86.59 & 10 & 0.45 & $5.18-26.53 \mathrm{ng} / \mathrm{ml}$ \\
\hline FSH & 5.47 & & 0.46 & $1.2-9 \mathrm{U} / \mathrm{L}$ \\
\hline LH & 1.62 & & 0.09 & $2-20 \mathrm{U} / \mathrm{L}$ \\
\hline Plasma morning cortisol & 5.6 & & 1.7 & $3.7-19.4 \mathrm{microgr} /$ \\
& & & & $5-46 \mathrm{pg} / \mathrm{ml}$ \\
\hline ACTH & 13.7 & & & $117-329 \mathrm{ng} / \mathrm{ml}$ \\
\hline IGF1 & 148.6 & $<10$ & & $<50 \mathrm{UI} / \mathrm{ml}$ \\
\hline Anti TPO antibodies & & $<20$ & & $<60 \mathrm{UI} / \mathrm{ml}$ \\
\hline Anti TG antibodies & & &
\end{tabular}


75 micrograms daily and cabergoline of weekly 1.25 miligrames (mg). After surgery she developed insipidus diabetes (that was remitted within months) and panhypopituitarism (with negative progesterone test) remained permanent. (Table I) Cranial CT scan performed within 8 months postoperatively reveals no pathologic changes. One year after surgery the patients has secondary amenorrhea (without therapy), intermittent mild headache and severe asthenia. Endocrine evaluation for of the functional reserve of the pituitary gland was performed and confirmed panhypopituitarism and inadequate control of thyroid function. (Table I) Levothyroxin was increased to 125 micrograms daily. The patient is currently undergoing treatment with levothyroxine, hydrocortisone and oral contraceptives. Close follow-up is necessary.

\section{Discussion}

Rathke cleft cyst (RCC) is a rare lesion accounting for about 1 percent of the total brain masses.[1,2,3] It can occur at any age although most are identified in adults as seen in our case. $[1,2]$ When its dimensions are under $1 \mathrm{~cm}$ usually the cyst does not produce symptoms. The most common signs are headache, visual disturbances, galactorrhea while diabetes insipidus is less common. $[5,10]$ Endocrine dysfunction is observed in $40-60 \%$ of the patients with a symptomatic RCC among which hypopituitarism is the most common. $[1,9,10]$ It appears due the compression of normal pituitary gland but inflammatory changes in the pituitary gland may also cause pituitary dysfunction.[8] Some authors appreciate that hypopituitarism appears up to $75-100 \%$ of the symptomatic cases while insipidus diabetes can reach $20 \%$.[5,6,7] In our case hypopituitarism was seen before the surgery and remained panhypopituitarism after the procedure while diabetes insipidus was iatrogenic. Headache is a frequent symptom of large Rathke's cleft cyst.[5] In this situation the patient has headache and visual disturbance (bilateral hemianopsia). These symptoms could be explained by the high dimension of the cyst (of $2.4 \mathrm{~cm}$ ), the suprasellar extension and the compression of the pituitary gland and optic chiasm as showed by MRI. Endocrine profile revealed ovarian and thyrotrophic insufficiency. After surgery the patient developed panhypopituitarism and transitory diabetes insipidus. A cause of pituitary insufficiency persistence is the irreversible impairment of pituitary gland because of the high compression and intra-operatory injury. The election treatment for symptomatic cases is transsphenoidal surgery with complete cyst evacuation and partial wall excision as the patient in our case. $[1,5,6]$ It has been reported that during the clinical course of RCC headache, visual disturbance, and pituitary dysfunction improved after surgery in $80-95 \%, 65-98 \%$, and $15-50 \%$ cases, respectively.[1,4,5,7,9] Some cranial nerves palsy has been reported in association to RCC but they are extremely rare.[11] Also selective gland incision seems to lower the endocrine impact of neurosurgery.[12] The risk of recurrence is higher in a suprasellar cyst location and size of the tumor, the finding of squamous metaplasia at pathological report of the cyst wall, and isointense features on T2weighted MRI while the extent and type of surgery approach are not at risk of recurrence based on some observations and others reported a higher risk in case of incomplete resection, intra-operative leak of cerebrospinal fluid, and in cases when an abdominal fat graft or sellar packing was necessary.[13,14] The real recurrence rate is unknown due to low number of adequate longitudinal studies.[14] Closely follow-up is necessary for each case of RCC regardless the age of diagnosis and the type of therapy.[15]

\section{Conclusion}

This case is highly suggestive for the underlying diagnosis of headache. The pituitary disturbances are caused by the tumour itself or by surgery and in this case they were permanent while the diabetes insipidus was transitory after surgical approach. 
Conflict of interest

None to declare.

\section{Acknowledgement} team.

We thank to the patient and the entire medical

\section{References}

1. Kim, E. (2012). Symptomatic rathke cleft cyst: clinical features and surgical outcomes. World Neurosurgery. 78(5), 527-534.

2. Shin, J.L., Asa, S.L., Woodhouse, L.J., Smyth, H.S. \& Ezzat, S. (1999). Cystic lesions of the pituitary: clinicopathological features distinguishing craniopharyngioma, Rathke's cleft cyst, and arachnoid cyst. Journal of Clinical Endocrinology and Metabolism. 84(11), 39723982.

3. Park, J.K., Lee, E.J. \& Kim, S.H. (2012). Optimal surgical approaches for Rathke cleft cyst with consideration of endocrine function. Neurosurgery. 70( ), 250-257.

4. Wait, S.D., Garrett,M.P., Little, A.S., Killory,B.D. \& White, W. L. (2010). Endocrinopathy, vision, headache, and recurrence after transsphenoidal surgery for rathke cleft cysts. Neurosurgery.67(3), 837-843.

5. El-Mahdy, W. \& Powell, M. (1998). Transsphenoidal management of 28 symptomatic Rathke's cleft cysts, with special reference to visual and hormonal recovery. Neurosurgery.
42(1), 7-17.

6. Eguchi, K., Uozimi, T., Arita, K., Kurisu,K., Yano, T., Sumida, M., Takechi, A. \& Pant, B. (1994). Pituitary function in patients with Rathke's cleft cyst: significance of surgical management. Endocrine Journal. 41(5), 535-540.

7. Aho, C.J., Liu, C., Zelman, V., Couldwell, W.T. \& Weiss, M.H. (2005). Surgical outcomes in 118 patients with Rathke cleft cysts. Journal of Neurosurgery.102(2), 189-193

8. Ross, D.A., Norman, D. \& Wilson. C.B. (1992). Radiologic characteristics and results of surgical management of Rathke's cysts in 43 patients. Neurosurgery. 30(2), 173-179.

9. Nishioka, H., Haraoka, J., Izawa, H. \& Ikeda, Y.. (2006).Headaches associated with Rathke's cleft cyst. Headache. 46(10), 1580-1586.

10. Rout, D., Das, L., Rao, V.R. \& Radhakrishnan, V.V. (1983). Symptomatic Rathke's cleft cysts. Surg Neurol. 19,42-45

11. Yum, H.R., Jang, J., Shin, S.Y. \& Park, S.H. (2015). Rathke cleft cyst presenting as unilateral progressive oculomotor nerve palsy. Can J Ophthalmol.50(2), 31-3. doi: 10.1016/j. jcjo.2014.11.017.

12. Barkhoudarian, G., Cutler, A.R., Yost, S., Lobo, B., Eisenberg, A. \& Kelly, D.F. (2015). Impact of selective pituitary gland incision or resection on hormonal function after adenoma or cyst resection. Pituitary. [Epub ahead of print]

13. Chotai, S., Liu, Y., Pan, J. \& Qi, S. (2015). Characteristics of Rathke's cleft cyst based on cyst location with a primary focus on recurrence after resection. J Neurosurg. 122(6), 1380-9. doi: 10.3171/2014.12.JNS14596.

14. Larkin, S., Karavitaki, N. \& Ansorge, O. (2014). Rathke's cleft cyst. Handb Clin Neurol. 124, 255 69. DOI: 10.1016/B978-0-444-59602-4.000174.

15. Oh, Y.J., Park, H.K., Yang, S., Song, J.H. \& Hwang, I.T., (2014). Clinical and radiological findings of incidental Rathke's cleft cysts in children and adolescents. Ann Pediatr Endocrinol Metab. 19(1), 20-6. doi: 10.6065/ apem.2014.19.1.20. Epub 2014 Mar 31. 